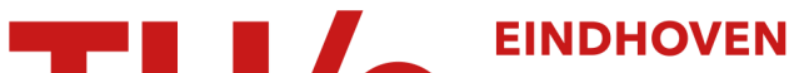 \\ UNIVERSITY OF \\ TECHNOLOGY
}

\section{Investigation of transient cavitating flow in viscoelastic pipes}

Citation for published version (APA):

Keramat, A., Tijsseling, A. S., \& Ahmadi, A. (2010). Investigation of transient cavitating flow in viscoelastic pipes. (CASA-report; Vol. 1039). Technische Universiteit Eindhoven.

Document status and date:

Published: 01/01/2010

\section{Document Version:}

Publisher's PDF, also known as Version of Record (includes final page, issue and volume numbers)

\section{Please check the document version of this publication:}

- A submitted manuscript is the version of the article upon submission and before peer-review. There can be important differences between the submitted version and the official published version of record. People interested in the research are advised to contact the author for the final version of the publication, or visit the $\mathrm{DOI}$ to the publisher's website.

- The final author version and the galley proof are versions of the publication after peer review.

- The final published version features the final layout of the paper including the volume, issue and page numbers.

Link to publication

\section{General rights}

Copyright and moral rights for the publications made accessible in the public portal are retained by the authors and/or other copyright owners and it is a condition of accessing publications that users recognise and abide by the legal requirements associated with these rights.

- Users may download and print one copy of any publication from the public portal for the purpose of private study or research.

- You may not further distribute the material or use it for any profit-making activity or commercial gain

- You may freely distribute the URL identifying the publication in the public portal.

If the publication is distributed under the terms of Article 25fa of the Dutch Copyright Act, indicated by the "Taverne" license above, please follow below link for the End User Agreement:

www.tue.nl/taverne

Take down policy

If you believe that this document breaches copyright please contact us at:

openaccess@tue.nl

providing details and we will investigate your claim. 
EINDHOVEN UNIVERSITY OF TECHNOLOGY

Department of Mathematics and Computer Science

\section{CASA-Report Io-39}

July 2010

Investigation of transient cavitating flow in viscoelastic pipes

by

A. Keramat, A.S. Tijsseling, A. Ahmadi

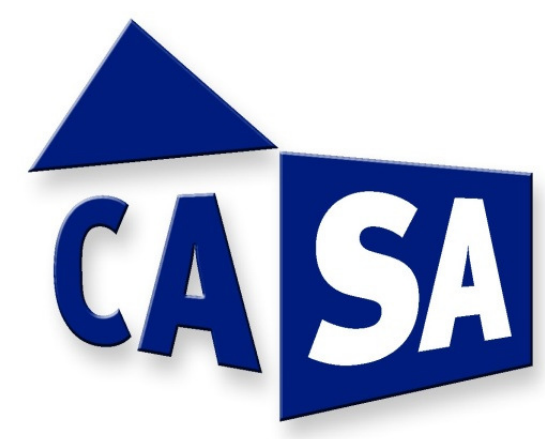

Centre for Analysis, Scientific computing and Applications

Department of Mathematics and Computer Science

Eindhoven University of Technology

P.O. Box 513

$5600 \mathrm{MB}$ Eindhoven, The Netherlands

ISSN: 0926-4507 



\title{
Investigation of transient cavitating flow in viscoelastic pipes
}

\author{
Alireza Keramat ${ }^{1}$, Arris S. Tijsseling ${ }^{2}$ and Ahmad Ahmadi ${ }^{3}$ \\ ${ }^{1} \mathrm{PhD}$ student, Department of Civil Engineering, Shahrood University of Technology, Iran; \\ presently, Department of Mathematics and Computer Science, Eindhoven University of Technology, \\ The Netherlands. E-mail address: a.keramat@tue.nl \\ ${ }^{2}$ Department of Mathematics and Computer Science, Eindhoven University of Technology, P.O. \\ Box 513, 5600 MB Eindhoven, The Netherlands, Tel.: +31 40247 2755; fax: +31 40244 2489. E- \\ mail address: a.s.tijsseling@tue.nl \\ ${ }^{3}$ Department of Civil Engineering, Shahrood University of Technology, Iran, Post Code: \\ 3619995161, University Boulevard, Shahrood, Iran, Fax: +98 273339 3336. E-mail address: \\ ahmadia97@yahoo.co.uk
}

\begin{abstract}
A study on water hammer in viscoelastic pipes when the fluid pressure drops to liquid vapour pressure is performed. Two important concepts including column separation and the effects of retarded strains in the pipe wall on the fluid response have been investigated separately in recent works, but there is some curiosity as to how the results for pressure and discharge are when column separation occurs in a viscoelastic pipe.

For pipes made of plastic such as polyethylene (PE) and polyvinyl chloride (PVC), viscoelasticity is a crucial mechanical property which changes the hydraulic and structural transient responses. Based on previous developments in the analysis of water hammer, a model which is capable of analysing column separation in viscoelastic pipes is presented and used for solving the selected case studies. For the column-separation modelling the Discrete Vapour Cavity Model (DVCM) is utilised and the viscoelasticity property of the pipe wall is modelled by Kelvin-Voigt elements.

The effects of viscoelasticity play an important role in the column separation phenomenon because it changes the water hammer fundamental frequency and so affects the time of opening or collapse of the cavities. Verification of the implemented computer code is performed for the effects of viscoelasticity and column separation - separately and simultaneously - using experimental results from the literature. In the provided examples the focus is placed on the simultaneous effect of viscoelasticity and column separation on the hydraulic transient response. The final conclusions drawn are that if rectangular grids are utilised the DVCM gives acceptable predictions of the phenomenon and that the pipe wall material's retarded behaviour strongly dampens the pressure spikes caused by column separation.
\end{abstract}

Keywords: Water Hammer, Viscoelasticity, Column Separation, Cavitating Flow, PVC Pipe.

\section{Introduction}

In recent years, the application of polymers such as polyethylene (PE), polyvinyl chloride (PVC) and acrylonitrile butadiene styrene (ABS) has highly increased in various parts of industry and especially in pipe systems. Some advantages including light weight, easy and fast installation, low price, and high chemical and abrasion resistance have motivated the designers to opt for the usage of viscoelastic materials in their designs.

Viscoelasticity is a property which is mainly manifested by the delay in the mechanical response of the material. For instance, in a viscoelastic bar, this property may be identified by creep behaviour when a constant stress is suddenly applied or relaxation when there is a constant strain. This behaviour has significant effects on the reaction of the system during dynamic loading. When the system is a pipeline loaded by the high and low pressures of water hammer, the effects of viscoelasticity are manifested by the radial expansion and contraction of the pipe wall which is accompanied by some delay relative to the fluctuating pressure. This property in the response of viscoelastic materials finally brings about a great damping of the fluid pressure. In elastic pipes, there is no delay between the pressure rise and the pipe radial expansion (or the pressure drop and the pipe radial contraction) and the hoop strain can be described as directly proportional to pressure. 
Basically, there are two general ways to make a mathematical model for viscoelastic materials: analysis in the frequency domain or in the time domain. The second way is appropriate for water-hammer because it is a transient phenomenon and due to the efficiency and robustness of the Method of Characteristics (MOC). In viscoelasticity the material has immediate and retarded responses following a loading. Elastic response is given by Hook's law and the retarded response is calculated using the superposition principle which is mathematically represented by a convolution integral. In pressurised viscoelastic pipes this integral contains the properties of flow and pipe and needs to be calculated for the whole duration of the transient response.

Covas et al. $[1,2,3]$ presented a model to deal with the dynamic effects of pipe-wall viscoelasticity in water hammer. The model included an additional term in the continuity equation to describe the retarded radial wall deformation that was based on a creep function fitted to experimental data. The governing equations were solved using MOC and it was argued that unlike the classical water-hammer model, a model that included viscoelastic wall behaviour could predict more accurately transient pressures. Related research in this field by Soares et al. [4] gave a general algorithm to include viscoelasticity and unsteady friction in the conventional MOC solution procedure. In this research an inverse model based on a two-step procedure was developed and used to determine the coefficients of the creep compliance function. The final conclusion of the work was that unsteady friction effects are negligible when compared to pipe-wall viscoelasticity.

Another phenomenon of high practical importance is column separation. It occurs during water hammer when the rarefaction wave causes the pressure to drop to vapour pressure and cavity bubbles emerge in the water. This strongly affects the pressure rises and drops. Column separation has been the subject of much research conducted worldwide. An extensive review of the subject has been performed by Bergant et al. [5]. The phenomenon was observed and its physical aspects were explained for the first time by Joukowsky in 1898. After that, various models based on graphic prediction of water hammer with column separation or some based on MOC were developed, until a model called DVCM - which is useful for computer implementation - was presented. A thorough analysis of column separation is complicated but the DVCM can provide favourable predictions of this phenomenon [5, 6]. The DVCM method is based on the consideration of cavities occurring only at the computational sections while the cavities are filled with vapour only, thus ignoring any gas content.

The retarded response of viscoelastic materials is commonly described by a convolution integral [7, 8] and so is unsteady friction. Consequently, their mathematical treatment is similar. Bergant et al. [9, 10], in a numerical investigation on the combination of unsteady friction and viscoelasticity, remarked that viscoelastic solutions obtained without unsteady friction provide favourable predictions for the damping observed in experiments. From this view, unsteady friction is ignored in the present study. References $[9,10]$ do not consider the combination of viscoelasticity and column separation studied herein.

As there is rare experimental or numerical work on column separation in viscoelastic pipes [12-16] and due to the prospering usage of this type of pipes, a study discussing this problem is of practical interest. Modelling and investigating the combined effects of viscoelasticity and column separation is the aim of this study. The developed model has been applied to various case studies including water hammer in a viscoelastic pipe without column separation as given by Covas et al. [2], column separation in an elastic pipe as given by Bergant et al. [11] and column separation in a viscoelastic pipe presented by Soares et al. [16]. In the latter, Soares et al. studied two methods including DVCM and DGCM for a PVC pipeline and compared each one with experimental results. The final conclusion was that the application of DVCM for viscoelastic pipes overpredicts pressures and the DGCM is more precise.

The results of this research may be helpful for designers of pipe systems who want to have a prediction of what could probably happen when column separation occurs in viscoelastic pipes.

\section{Mathematical model}

First the basic concepts of viscoelasticity in water hammer, and the way to mathematically describe it, are given. Then, the governing equations for water hammer with column separation in a viscoelastic pipe are presented. The assumptions made in making the mathematical model are related to those associated with the theory of water hammer and column separation. In the water-hammer model the relevant assumptions are: no FSI, no unsteady friction, thin-walled pipe and neglecting convective terms.

The DVCM is used for modelling column separation so that the governing equations are those of classical water hammer with an additional continuity equation in each computational section to calculate possible cavity volumes. Zero and non-zero volumes distinguish the occurrence of column separation at each time and location. Assumptions underlying for this model are discussed when the model is presented in the subsequent sections.

\subsection{Viscoelasticity}

Viscoelasticity concerns a mechanical response involving aspects of both elastic solids and viscous fluids. The elastic behaviour of viscoelastic materials is modelled using springs, while dashpots are used to model the viscous behaviour. By using various combinations of spring and dashpot elements in series and/or parallel, a wide range of linear viscoelastic materials can be described. Figure 1-a shows the Kelvin-Voigt model, consisting of one element. It often does not provide a satisfactory prediction of observed viscoelastic responses. The generalized Kelvin-Voigt model depicted in Fig 1-b is a more reliable tool. It consists of $N_{K V}$ Kelvin-Voigt elements connected in series together with one additional spring $(E)$.

Basically, the relation between stress $\sigma$ and strain $\varepsilon$ for linear viscoelastic materials involves higher-order (and even fractional) time derivatives of both stress and strain. An alternative representation for this relation while using the Boltzmann superposition principle [7] is:

$$
\varepsilon(t)=\sigma(t) J(0)+\int_{0}^{t} \sigma(t-s) \frac{d J(s)}{d s} d s=\sigma(t) J(0)+\left(\sigma * \frac{d J}{d t}\right)(t)=(\sigma * d J)(t)=(J * d \sigma)(t),
$$

in which “*” is the convolution operator and “* $d$ " is the Stieltjes convolution operator which includes the term $\sigma(t) J(0)$ 
representing the immediate response. The creep compliance function $J(t)$ corresponding to the generalized Kelvin-Voigt model is defined by

$$
J(t):=J_{0}+\sum_{k=1}^{N_{K V}} J_{k}\left(1-e^{-\frac{t}{\tau_{k}}}\right)
$$

where $J_{0}:=1 / E$ represents the elastic response of the material, $J_{k}$ defined by $J_{k}:=1 / E_{k}$ is the creep compliance and $E_{k}$ is the modulus of elasticity of the $k$-th spring and $\tau_{k}:=\mu_{k} / E_{k}$ is the retardation time and $\mu_{k}$ is the viscosity of the $k$-th dashpot.
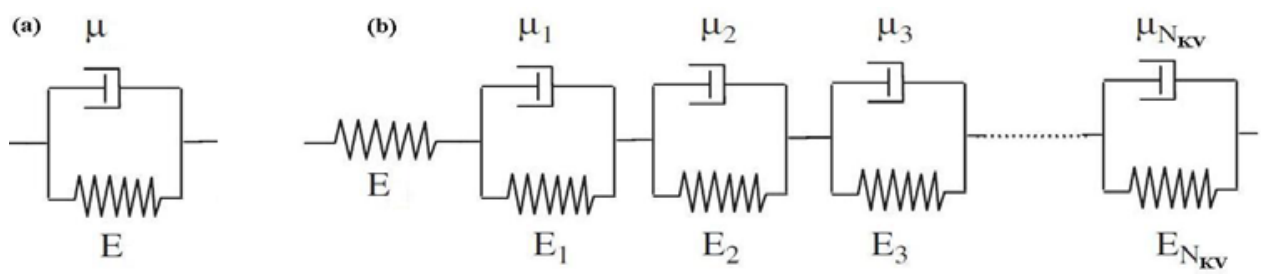

Fig. 1 Mechanical representation for a viscoelastic solid: (a) Kelvin-Voigt element (b) generalized Kelvin-Voigt model.

Relation (1) holds for uni-axial loading. If one wants to extend it to three-directional loading, then deformations related to Poisson's ratio $v$ have to be taken into account. According to Stieltjes convolution notation the three-directional constitutive relations between stress and strain in the $z$ - and $\phi$-directions of an $(r, \phi, z)$ cylindrical coordinate system are (pipe's central axis is along $z$ )

$$
\begin{aligned}
& \varepsilon_{z}=\sigma_{z} * d J-v\left(\sigma_{\phi} * d J\right), \\
& \varepsilon_{\phi}=\sigma_{\phi} * d J-v\left(\sigma_{z} * d J\right)
\end{aligned}
$$

These relations ignore the pipe's radial stress $\left(\sigma_{r}=0\right)$ and possible time dependency of $v$.

Relation (1) indicates that the total strain consists of an elastic and a viscoelastic part. The viscoelastic part is a function of the whole loading history. In the case of water hammer, this loading comes from the fluid pressure head $H$ within the pipe. In reality, one can assume that a long time has been passed after the establishment of the steady head $H_{0}$, so $H_{0}$ accounts for the static situation. If the dynamic head $\tilde{H}=H-H_{0}$ is substituted for stress $\sigma$ in the integrand of equation (1), a function which represents up to a constant factor the retarded response to water hammer is given by:

$$
I_{\tilde{H}}(t):=\int_{0}^{t} \tilde{H}(t-s) \frac{d J(s)}{d s} d s=\sum_{k=1}^{N_{K V}}\left(\frac{J_{k}}{\tau_{k}} \int_{0}^{t} \tilde{H}(t-s) e^{-\frac{s}{\tau_{k}}} d s\right):=\sum_{k=1}^{N_{K V}} I_{\tilde{H} k}(t) .
$$

\subsection{Governing equations}

The continuity and momentum equations describing water hammer are:

$$
\begin{aligned}
& \frac{1}{A} \frac{\partial Q}{\partial z}+\frac{\rho g}{K} \frac{\partial H}{\partial t}+2 \frac{\partial \varepsilon_{\phi}}{\partial t}=0 \\
& \frac{1}{A} \frac{\partial Q}{\partial t}+g \frac{\partial H}{\partial z}=\frac{-f Q|Q|}{2 D A^{2}}
\end{aligned}
$$

in which $z$ is the axial coordinate, $t$ is time, $g$ is the gravitational acceleration, $\rho$ is the fluid density, $Q$ is the discharge, $K$ is the bulk modulus of the fluid, $A$ is the cross-sectional area, $D$ is the inner diameter, $f$ is the friction coefficient and $\varepsilon_{\phi}$ is the circumferential strain. The last term in equation (6) describes the rate of hoop strain including both elastic and viscoelastic behaviour. The hoop strain in elastic pipes is directly proportional to pressure, but in viscoelastic pipes a time delay occurs.

One important assumption made in this study is that the pipe is totally restrained from axial movements, so that $\varepsilon_{z}=0$. This leads in equation (3) to:

$$
\sigma_{z} * d J=v\left(\sigma_{\phi} * d J\right)
$$

If this is substituted in equation (4) the circumferential or hoop strain in thin-walled pipes $\left(\sigma_{r}=0\right)$ is given by

$$
\varepsilon_{\phi}=\left(1-v^{2}\right)\left(\sigma_{\phi} * d J\right)
$$

The thin-walled pipe assumption also allows the dynamic circumferential hoop stress to be calculated according to:

$$
\sigma_{\phi}=\frac{\rho g D \tilde{H}}{2 e}
$$

where $e$ is the thickness of the pipe wall. With the equations (9) and (10), the continuity equation (6) reduces to

$$
\frac{1}{A} \frac{\partial Q}{\partial z}+\frac{\rho g}{K} \frac{\partial H}{\partial t}+\left(1-v^{2}\right) \frac{\rho g D}{e} \frac{\partial}{\partial t}(\tilde{H} * d J)=0 .
$$

Using equation (5) and the Stieltjes convolution operator (equation (1)), this can be written as 


$$
\frac{1}{A} \frac{\partial Q}{\partial z}+\frac{g}{c^{2}} \frac{\partial H}{\partial t}=-\left(1-v^{2}\right) \frac{\rho g D}{e} \frac{\partial I_{\tilde{H}}}{\partial t}
$$

where $c$ is the classical pressure wave speed given by

$$
c=\left(\rho\left(\frac{1}{K}+\left(1-v^{2}\right) \frac{D}{e E}\right)\right)^{-\frac{1}{2}} .
$$

The equations (7) and (12) for the two unknowns $H$ and $Q$ are solved by the numerical scheme presented in Section 3.Vapour cavities are allowed to form at all computational sections when the pressure drops to the vapour pressure. Cavity volumes $\forall$ are then calculated using the continuity equation for each cavity point:

$$
\frac{\partial \forall}{\partial t}=Q-Q_{u},
$$

where $Q_{u}$ and $Q$ are the discharges upstream and downstream of the cavity.

\section{Numerical solution}

By applying the MOC solution procedure to the equations (7) and (12), they are transformed into two first-order ordinary differential equations (ODE) which are valid along the two characteristic lines $\mathrm{C}^{+}$and $\mathrm{C}^{-}$in the distance-time plane. Then the ODEs are written in finite-difference form. The terms on the right-hand side of these equations are written as direct functions of the unknowns of the current time step so that the convolution terms are absent in the finite-difference discretisation. Looking at the equations (12) and (5), the first term to be evaluated for the unknowns of the current time step is:

$\frac{\partial I_{\tilde{H}}}{\partial t}=\sum_{k=1}^{N_{K V}} \frac{\partial I_{\tilde{H} k}}{\partial t}=\sum_{k=1}^{N_{K V}} \frac{J_{k}}{\tau_{k}} \frac{\partial}{\partial t}\left(\int_{0}^{t} \tilde{H}(t-s) e^{-\frac{s}{\tau_{k}}} d s\right)=\sum_{k=1}^{N_{K V}} \frac{J_{k}}{\tau_{k}}\left(-\frac{1}{\tau_{k}} \int_{0}^{t} \tilde{H}(t-s) e^{-\frac{s}{\tau_{k}}} d s+\tilde{H}(t)\right)=\sum_{k=1}^{N_{K V}}\left(-\frac{I_{\tilde{H} k}(t)}{\tau_{k}}+\frac{J_{k}}{\tau_{k}} \tilde{H}(t)\right)$

In equation (15), to derive the third expression from the second one, $(t-s)$ is defined as a new variable, and then its time derivative is taken using the product rule. Integral $I_{\tilde{H} k}$ (defined in equation (5)) is approximated by its value at the previous time step plus its change in the last time increment. Equation (15) eventually leads to the following linear relation for the unknown $H(t)$ (head at the current time step) that can be directly applied in the compatibility equations:

$$
\frac{\partial I_{\tilde{H}}(t)}{\partial t} \approx\left(H(t)-H_{0}\right) \sum_{k=1}^{N_{K V}} \frac{J_{k}}{\Delta t}\left(1-e^{-\frac{\Delta t}{\tau_{k}}}\right)+\tilde{H}(t-\Delta t) \sum_{k=1}^{N_{K V}}\left(\frac{J_{k}}{\tau_{k}} e^{-\frac{\Delta t}{\tau_{k}}}-\frac{J_{k}}{\Delta t}\left(1-e^{-\frac{\Delta t}{\tau_{k}}}\right)\right)-\sum_{k=1}^{N_{K V}} \frac{e^{-\frac{\Delta t}{\tau_{k}}}}{\tau_{k}} I_{\tilde{H} k}(t-\Delta t):=a_{1} H(t)+a_{2},
$$

where

$$
I_{\tilde{H} k}(t-\Delta t) \approx \tilde{H}(t-\Delta t)\left(J_{k}-\frac{J_{k} \tau_{k}}{\Delta t}\left(1-e^{-\frac{\Delta t}{\tau_{k}}}\right)\right)+\tilde{H}(t-2 \Delta t)\left(-J_{k} e^{-\frac{\Delta t}{\tau_{k}}}+\frac{J_{k} \tau_{k}}{\Delta t}\left(1-e^{-\frac{\Delta t}{\tau_{k}}}\right)\right)+e^{-\frac{\Delta t}{\tau_{k}}} I_{\tilde{H} k}(t-2 \Delta t) .
$$

In the implementation, the summations which are independent of the unknowns are calculated only once outside the main loop. As a result, employing more Kelvin-Voigt elements does not increase the simulation time significantly. The equations along the characteristic lines $\mathrm{C}^{+}$and $\mathrm{C}^{-}$become

$$
\begin{aligned}
& Q_{u}(t)=-B H(t)+B H_{A 1}+Q_{A 1}+\left(\frac{A \rho g D\left(1-v^{2}\right) \Delta x}{e}\left(a_{1} H(t)+a_{2}\right)-R \Delta t\left|Q_{A 1}\right| Q_{u}(t)\right), B=\frac{A g}{c}, R=\frac{f}{2 D A}, \Delta x=c \Delta t, \\
& Q(t)=B H(t)-B H_{A 2}+Q_{u A 2}-\left(\frac{-A \rho g D\left(1-v^{2}\right) \Delta x}{e}\left(a_{1} H(t)+a_{2}\right)+R \Delta t\left|Q_{u A 2}\right| Q(t)\right), \Delta x=-c \Delta t .
\end{aligned}
$$

In the compatibility equations (18) and (19) unknowns holding the index $\mathrm{A} 1$ (A2) correspond to points on line $\mathrm{C}^{+}\left(\mathrm{C}^{-}\right)$at the previous time step $(t-\Delta t)$. The nonlinear term appearing on the right-hand-side of equation (7) is linearised by using the calculated $Q$-values of the earlier time step. After simplification, the equations (18) and (19) can be written as

$$
\begin{aligned}
& Q_{u}(t)=-\frac{B+C_{p 2}^{\prime \prime \prime}}{1+C_{p 2}^{\prime}} H(t)+\frac{Q_{A 1}+B H_{A 1}+C_{p 1}^{\prime \prime \prime}}{1+C_{p 2}^{\prime}}, C_{p 2}^{\prime \prime \prime}=\frac{D}{e} \operatorname{A\rho g}\left(1-v^{2}\right) c \Delta t a_{1}, C_{p 2}^{\prime}=R\left|Q_{A 1}\right| \Delta t, C_{p 1}^{\prime \prime \prime}=\frac{D}{e} \operatorname{A\rho g}\left(1-v^{2}\right) c \Delta t a_{2}, \\
& Q(t)=\frac{B+C_{n 2}^{\prime \prime \prime}}{1+C_{n 2}^{\prime}} H(t)+\frac{Q_{u A 2}-B H_{A 2}+C_{p 1}^{\prime \prime \prime}}{1+C_{p 2}^{\prime}}, C_{n 2}^{\prime \prime \prime}=C_{p 2}^{\prime \prime \prime}, C_{n 2}^{\prime}=R\left|Q_{u A 2}\right| \Delta t, C_{n 1}^{\prime \prime \prime}=-C_{p 1}^{\prime \prime \prime},
\end{aligned}
$$

where superscripts ' and "' refer to the quasi-steady friction and the pipe viscoelastic terms, respectively; they are chosen to be consistent with the formulas given by Soares et al. [4]. The discharges at the upstream $\left(Q_{u}\right)$ and downstream $(Q)$ sides of each computational section have been introduced to accommodate column separation. They are identical when the calculated pressure is above the vapour pressure. Cavity volumes grow and shrink at computational sections when vapour pressure prevails. If the cavity volume becomes zero or negative, the computation returns to the standard water-hammer calculation. The numerical integration scheme for the continuity equation (14) for staggered grids has the form $[5,11]$

$$
\forall(t)=\forall(t-2 \Delta t)+2 \Delta t\left\{\psi\left[Q(t)-Q_{u}(t)\right]+(1-\psi)\left[Q(t-2 \Delta t)-Q_{u}(t-2 \Delta t)\right]\right\},
$$


in which $\psi$ is a weighting factor. If $\psi$ is 0.5 , then equation (22) is the trapezoidal rule which has second-order accuracy. This value of $\psi$ also determines the stability or instability of the finite-difference scheme. Simpson and Bergant [17] performed numerical computations taking $\psi$ values in the range from 0.5 to 1.0 and found that when using a $\psi$ close to 1.0 , unwanted pressure spikes were damped significantly, but the accuracy is first order. In this study $\psi=0.5+2 \Delta t$ is taken to obtain both stability and secondorder accuracy.

\subsection{Rectangular versus staggered grids}

A rectangular grid in classical waterhammer (without column separation) is in fact a combination of two separate staggered grids. Comparison of results with column separation based on staggered and rectangular grids shows that some of the oscillations in the graphs calculated with a rectangular grid are not genuine and introduced due to inappropriate coupling of staggered grids (which happens in the calculation of cavity volumes when $\Delta t$ instead of $2 \Delta t$ is used in equation (22)). To calculate the cavity volumes it is therefore recommended to employ the values of each of the staggered grids per se, otherwise additional numerical oscillations (spurious pressure spikes), which is an issue in DVCM, will occur. Accordingly, relation (22) given for staggered grids, is proposed to obtain the cavity volumes.

According to relation (16), it is required to approximate the time derivative of the existing convolution integral. To numerically calculate the time derivative, the values at the previous time step have been used and this necessitated the use of a rectangular grid. Otherwise, by using the values of two time step earlier (as in staggered grids), the accuracy will be somewhat diminished. The approach taken in relation (22) is not needed here, because viscoelasticity has a dampening effect and numerical oscillations are not an issue.

The taken rectangular-grid approach gives good numerical results compared to the experiments, although the presented timehistories are those of one staggered grid (i.e. half of the rectangular grid) (this is a numerical filter). Otherwise, some spurious oscillations appear in the results. The present implementation of DVCM in viscoelastic pipes leads to a different prediction of the pressure attenuations than in [16]. This is mainly due to the sensitivity of DVCM to its numerical implementation.

\section{Numerical results and discussion}

The numerical solution presented in Section 3 has been implemented in MATLAB. Simulations can be done with or without the effects of viscoelasticity or column separation. First, appropriate case studies are solved to validate the proper implementation of viscoelasticity and column separation. Then another example is presented to study and compare the effects of each or both on water hammer.

\subsection{Validation}

The three possible choices of analysis are validated against three appropriate well-known experiments.

\subsubsection{Water hammer with column separation in an elastic pipe in Adelaide experiment.}

In this subsection, the numerical results obtained without viscoelasticity for a copper-pipeline installed in the Robin Hydraulic Laboratory at the University of Adelaide, Australia, are provided. To verify the proper implementation of the DVCM, the numerical results are also compared against the verified results of DVCM given by Bergant et al. [11]. Specifications of the pipe system are listed in Table 1.

Table 1. Specification of the reservoir-pipe-valve experiment, Bergant et al. [11].

\begin{tabular}{|c|c|c|c|c|c|c|c|c|c|}
\hline Length & $\begin{array}{c}\text { Inner } \\
\text { diameter }\end{array}$ & $\begin{array}{c}\text { Steady state } \\
\text { velocity }\end{array}$ & $\begin{array}{c}\text { Reservoir } \\
\text { head }\end{array}$ & $\begin{array}{c}\text { Time of valve } \\
\text { closure }\end{array}$ & $\begin{array}{c}\text { Friction } \\
\text { coefficient }\end{array}$ & $\begin{array}{c}\text { Reservoir } \\
\text { elevation }\end{array}$ & $\begin{array}{c}\text { Valve } \\
\text { elevation }\end{array}$ & $\begin{array}{c}\text { Vapour } \\
\text { head }\end{array}$ & $\begin{array}{c}\text { Wave } \\
\text { speed }\end{array}$ \\
\hline $\begin{array}{c}37.23 \\
\mathrm{~m}\end{array}$ & $22 \mathrm{~mm}$ & $\begin{array}{c}0.3 \mathrm{~m} / \mathrm{s} \text { or } \\
1.4 \mathrm{~m} / \mathrm{s}\end{array}$ & $22 \mathrm{~m}$ & $0.009 \mathrm{~s}$ & $\begin{array}{c}0.045 \text { or } \\
0.037\end{array}$ & $0.0 \mathrm{~m}$ & $2.03 \mathrm{~m}$ & $-10.25 \mathrm{~m}$ & $\begin{array}{c}1319 \\
\mathrm{~m} / \mathrm{s}\end{array}$ \\
\hline
\end{tabular}

This example is solved for two different initial flow velocities $V_{0}=0.3 \mathrm{~m} / \mathrm{s}$ and $V_{0}=1.4 \mathrm{~m} / \mathrm{s}$. Computational and measured results presented in [11] are compared with those of the current research in Figs 2 and 3. The number of reaches in the simulation is 32 and the time step $\Delta t$ is $0.88 \mathrm{~ms}$.
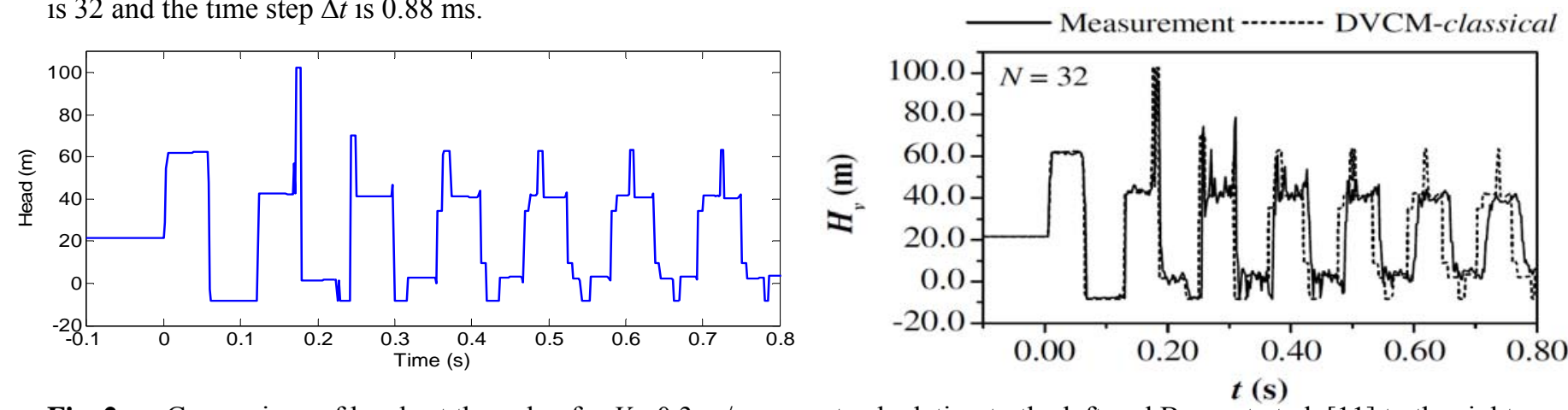

Fig. 2 Comparison of heads at the valve for $V_{0}=0.3 \mathrm{~m} / \mathrm{s}$, current calculation to the left and Bergant et al. [11] to the right. 

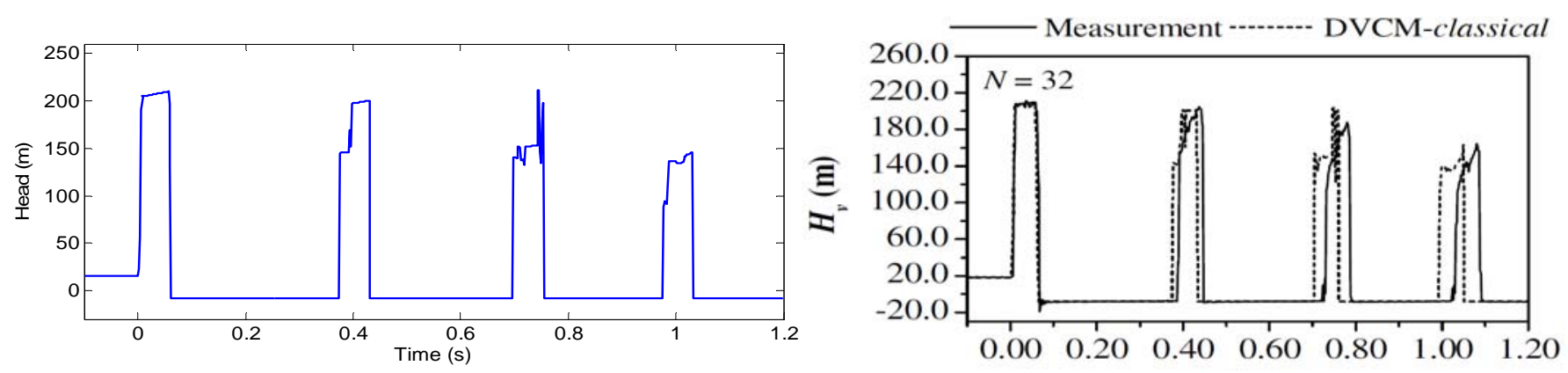

Fig. 3 Comparison of heads at the valve for $V_{0}=1.4 \mathrm{~m} / \mathrm{s}$, current calculation to the left and Bergant et al. [11] to the right.

The small differences between the numerical results in the left and right graphs mostly are attributed to small differences in the valve-closure pattern which plays an important role in the initiation and collapse of the cavities. This is confirmed by numerical results obtained with slightly different valve closing times. The best way to remove the effects of valve closing models (which play an important role in the column separation results, especially at the later water-hammer periods), when experimental and numerical results are compared, is to use measured pressures as input in the numerical simulations up to the time of the valve's full closure.

\subsubsection{Water hammer in a viscoelastic pipe in Imperial College experiment.}

To verify the proper implementation of the viscoelasticity effect, the case study presented by Covas et al. [1, 2, 3], in which column separation did not occur, was solved. It was found that the current results (not shown) were in good agreement with those given by Covas et al. [2]. This case study is further investigated through extended simulations in Section 4.2.

\subsubsection{Water hammer with column separation in a viscoelastic pipe in Lisbon experiment.}

The experiment with column separation in a viscoelastic pipeline performed by Soares et al. [16] is simulated here. It consists of a valve-pipe-reservoir system in which water hammer is initiated by fast closure of the upstream valve. Specifications of the system are given in Table 2. Numerical results of the present method are compared with the experimental and numerical results by Soares et al. [16] in Figs 4 and 5. From the results in [16], the friction coefficient and upstream steady head are estimated as $f=$ 0.01814 and $H_{0, \text { val }}=30.7 \mathrm{~m}$; the downstream constant head and vapour pressure have values $1.6 \mathrm{~m}$ and $-10 \mathrm{~m}$, respectively.

Table 2. Specification of the valve-pipe-reservoir experiment, Soares et al. [16]

\begin{tabular}{|c|c|c|c|c|c|c|c|c|}
\hline Length & $\begin{array}{c}\text { Inner } \\
\text { diameter }\end{array}$ & $\begin{array}{l}\text { Steady state } \\
\text { discharge }\end{array}$ & $\begin{array}{l}\text { Reynolds number of } \\
\text { steady flow }\end{array}$ & $\begin{array}{l}\text { Time step in } \\
\text { simulation }\end{array}$ & $\begin{array}{l}\text { Wave } \\
\text { speed }\end{array}$ & \multicolumn{3}{|c|}{$\begin{array}{l}\text { Creep compliance coefficients } \\
\qquad J_{k}\left(10^{-9} \mathrm{~Pa}^{-1}\right)\end{array}$} \\
\hline \multirow{2}{*}{$203 \mathrm{~m}$} & \multirow{2}{*}{$44 \mathrm{~mm}$} & \multirow{2}{*}{$41 / s$} & \multirow{2}{*}{120,000} & \multirow{2}{*}{$0.08 \mathrm{~s}$} & \multirow{2}{*}{$250 \mathrm{~m} / \mathrm{s}$} & $\tau_{1}=0.1 \mathrm{~s}$ & $\tau_{2}=0.5 \mathrm{~s}$ & $\tau_{3}=3 \mathrm{~s}$ \\
\hline & & & & & & $J_{1}=0.6$ & $J_{2}=0.35$ & $J_{3}=0.5$ \\
\hline
\end{tabular}
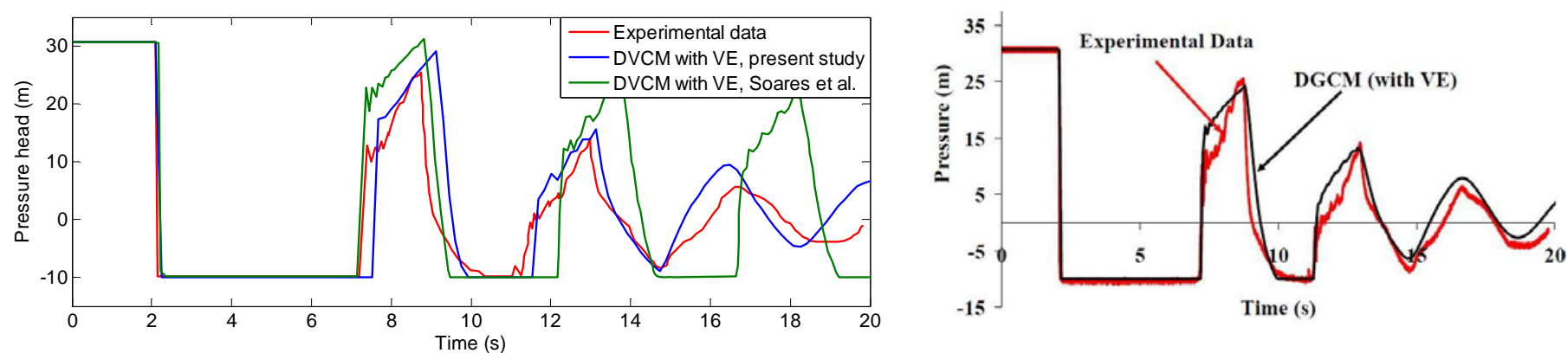

Fig. 4 Left: experimental [16] and numerical results (DVapourCM with viscoelasticity) at the valve; right: experimental and numerical results (DGasCM with viscoelasticity) at the valve extracted from [16].
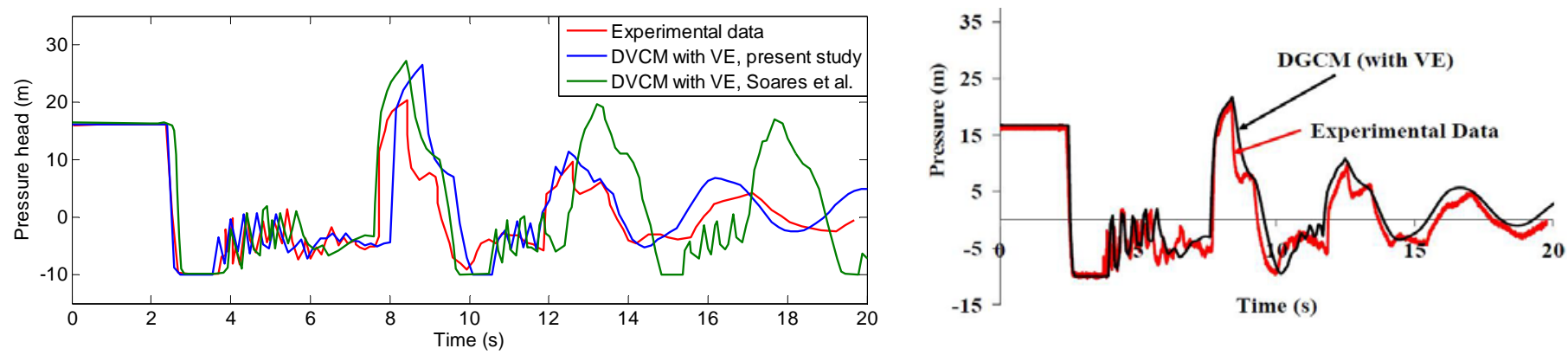

Fig. 5 Left: experimental [16] and numerical results (DVapourCM with viscoelasticity) at the midpoint; right: experimental and numerical results (DGasCM with viscoelasticity) at the midpoint extracted from [16]. 
As Figs 4 and 5 show, the application of DVCM for studying column separation in viscoelastic pipes gives an acceptable prediction of the real situation in view of the simplicity of the model. Its deficiency is mostly in not being accurate in the timing of collapse and opening of cavities. This in return affects the magnitudes of pressure rise following cavity collapse. This is the most important weakness of DVCM. The modelling of unsteady friction might improve the results in this respect [18]. Bergant et al. [11] studied another possible remedy to overcome it. The present DVCM is closer to the experiment than that in [16] (not shown) due to the different numerical implementation of DVCM in viscoelastic pipes (see subsection 3.1). Looking at the time scale of the experiment, the issue of air coming out of solution must be taken into consideration [19]. Experimental uncertainties, cavitation randomness and temperature effects are other issues.

\subsection{Numerical results}

The Imperial College experiment $[1,2,3]$ is simulated with and without viscoelasticity, and with and without column separation. The physical experiment is without column separation, but has been chosen here because calibrated creep functions are available. Specifications of the system are listed in Table 3. When viscoelasticity is taken into account the calibrated coefficients in Table 4, determined by inverse calculation in [2], are used in the simulation. The results of each numerical simulation are given at locations 1 and 8 corresponding to distances $271 \mathrm{~m}$ and $116.5 \mathrm{~m}$ from the upstream end. In some simulations the reservoir head, discharge and friction were changed (with respect to the experiment) to generate column separation and severe cavitation; they are marked by the sign $\times$ in Table 3 .

Table 3. Specification of the reservoir-pipe-valve experiment, Covas et al. $[1,2,3] ; \times=$ value different from the physical experiment.

\begin{tabular}{|c|c|c|c|c|c|c|}
\hline Length & Inner diameter & $\begin{array}{c}Q=\text { Steady state } \\
\text { discharge }\end{array}$ & Reservoir head $^{\times}$ & Friction coefficient ${ }^{\times}$ & Wave speed & $\begin{array}{c}\text { Reservoir and pipeline } \\
\text { elevation }\end{array}$ \\
\hline $277 \mathrm{~m}$ & $50.6 \mathrm{~mm}$ & $1.01 \mathrm{l} / \mathrm{s}$ & $45 \mathrm{~m}$ & 0.02 & $395 \mathrm{~m} / \mathrm{s}$ & $0 \mathrm{~m}$ \\
\hline
\end{tabular}

Table 4. Creep coefficients $J_{k}$ for the Imperial College test with $Q_{0}=1.011 / \mathrm{s}$ and $c=395 \mathrm{~m} / \mathrm{s}$ calibrated without unsteady friction $[2]$.

\begin{tabular}{|c|c|c|c|c|c|c|}
\hline Sample size & $\begin{array}{c}\text { Number of K.V. } \\
\text { elements }\end{array}$ & \multicolumn{3}{|c|}{ Retardation times $\tau_{k}$ and creep coefficients $J_{k}\left(10^{-10} \mathrm{~Pa}^{-1}\right)$} \\
\hline \multirow{2}{*}{$20 \mathrm{~s}$} & 5 & $\tau_{1}=0.05 \mathrm{~s}$ & $\tau_{2}=0.5 \mathrm{~s}$ & $\tau_{3}=1.5 \mathrm{~s}$ & $\tau_{4}=5 \mathrm{~s}$ & $\tau_{5}=10 \mathrm{~s}$ \\
\cline { 2 - 6 } & $J_{1}=1.057$ & $J_{2}=1.054$ & $J_{3}=0.9051$ & $J_{4}=0.2617$ & $J_{5}=0.7456$ \\
\hline
\end{tabular}

\subsubsection{Column separation without viscoelasticity in Imperial College test.}

If the Imperial College test done by Covas et al. [1, 2, 3] is simulated without the effects of viscoelasticity but with column separation, then the results are as shown in Figs 6 and 7. Fig 6 shows the results of a numerical simulation with initial discharge $Q_{0}=1.01 \mathrm{l} / \mathrm{s}$ and $3 \mathrm{~m}$ reservoir head (friction factor $f=0.01$ ) while Fig 7 is for $Q=3.03 \mathrm{l} / \mathrm{s}$ and $7 \mathrm{~m}$ reservoir head $(f=0.02$ ). The dotted lines are the results of classical water-hammer. In Fig 7 severe cavitation occurs. In this case the pressure drop due to the negative Joukowsky pressure is much below the vapour pressure $(-10.25 \mathrm{~m})$ causing the cavity bubbles to form along the pipeline advancing toward the upstream end. These results are given as a reference for those presented in the next subsection to distinguish each modelled effect.
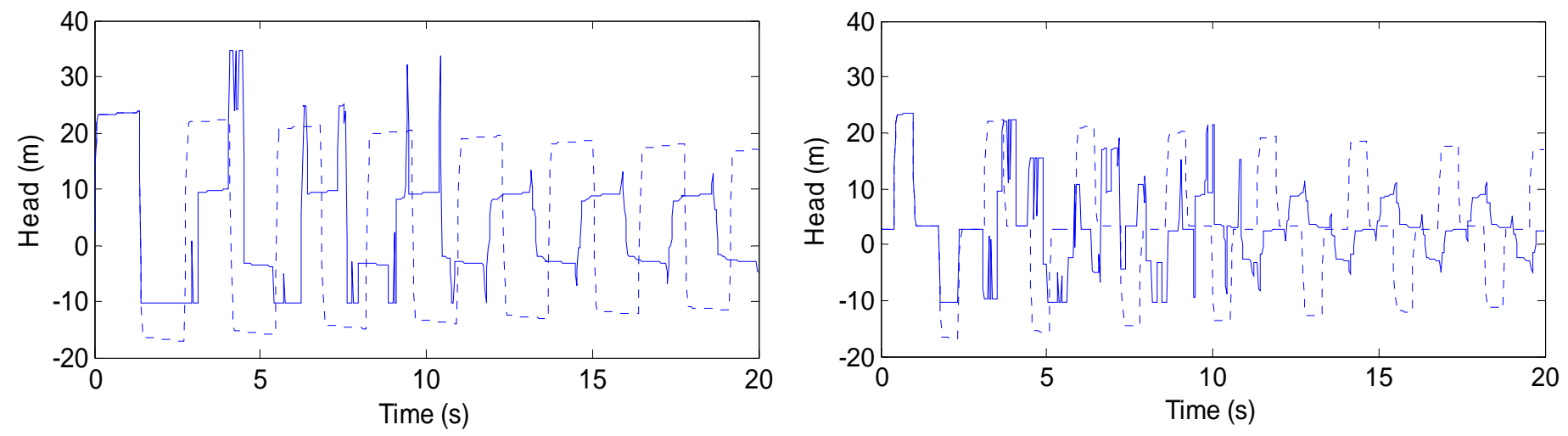

Fig. 6 Results for column separation in Imperial College test if the pipeline is elastic $(Q=1.011 / \mathrm{s}$ and $3 \mathrm{~m} \mathrm{reservoir}$ head), head at the valve to the left and at location 8 to the right. Dotted lines correspond to pure water hammer. 

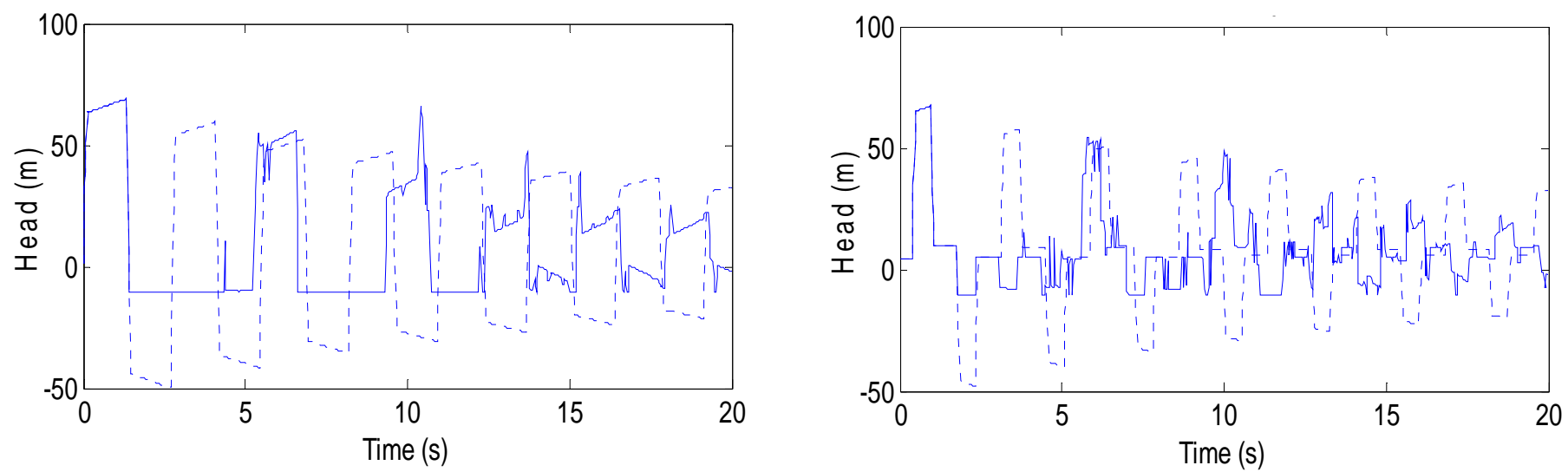

Fig. 7 Results for column separation in Imperial College test if the pipeline is elastic $(Q=3.031 / \mathrm{s}$ and $7 \mathrm{~m}$ reservoir head), head at the valve to the left and at location 8 to the right. Dotted lines correspond to pure water hammer.

\subsubsection{Column separation with viscoelasticity in Imperial College experiment.}

Results with both viscoelasticity and column separation are shown now. Figure 8 corresponds to the situation in which the reservoir head is $3 \mathrm{~m}$ so that the water-hammer pressure-drop brings about column separation. It takes about half of the fundamental period, i.e. $2 L / c$, until the rarefaction wave reaches the valve and initiates cavitation. During this time, viscoelasticity damps out the high pressures significantly and the column separation is by far not as serious as seen in Fig 6 for an elastic pipeline.
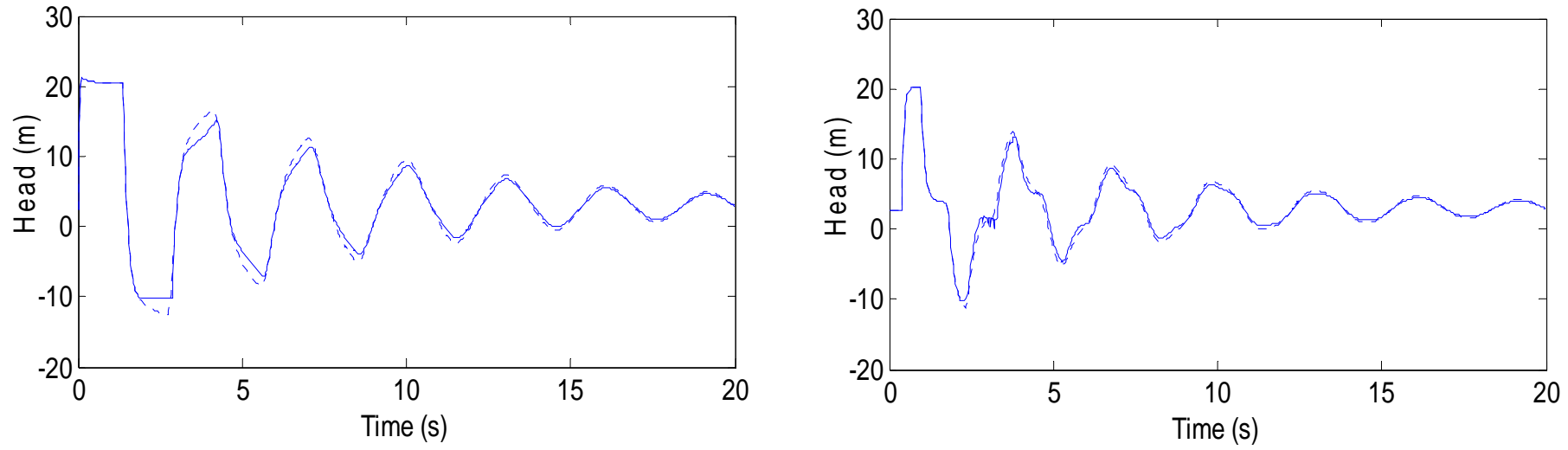

Fig. 8 Results for column separation in Imperial College test $(Q=1.01 \mathrm{l} / \mathrm{s}$ and $3 \mathrm{~m}$ reservoir head), head at the valve to the left and at location 8 to the right. Dotted lines correspond to water hammer without column separation.

Results for severe cavitation occurring with $Q=3.03 \mathrm{l} / \mathrm{s}$ and a reservoir head of $7 \mathrm{~m}$ in the viscoelastic pipe are presented in Fig 9. The second pressure rise at the valve following the first cavity collapse happens at time $t=4.4 \mathrm{~s}$. This time is earlier (except for a spike) than in the elastic model ( $t=5.3 \mathrm{~s}$, see Fig 7-left). One explanation is that the water-hammer wave is significantly damped during the first half of the cycle, resulting in a weaker rarefaction wave. This in turn leads to a smaller cavity at the valve, which takes less time to collapse.
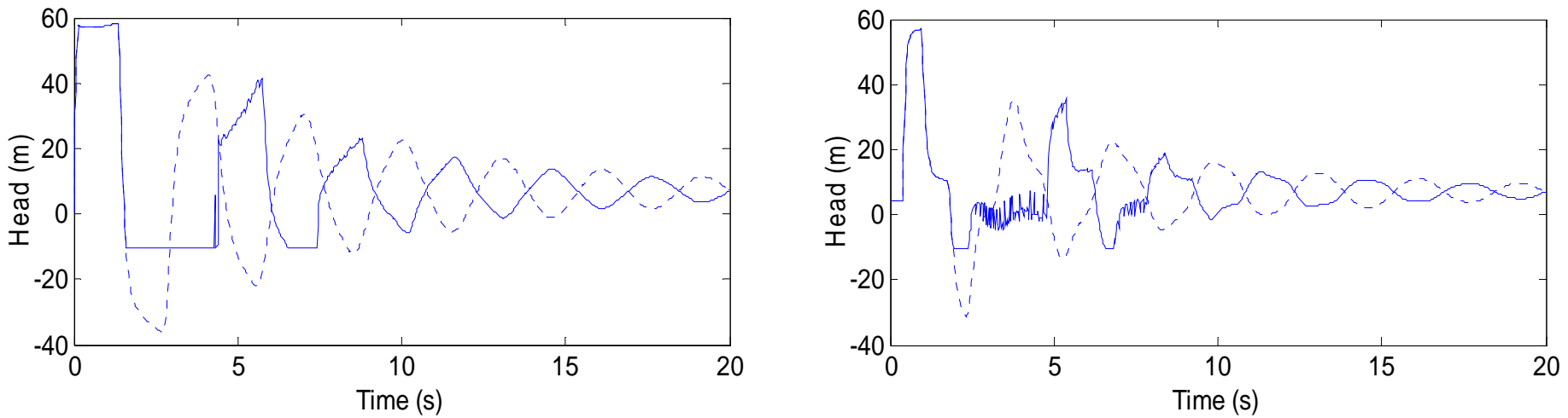

Fig. 9 Results for column separation in Imperial College test $(Q=3.03 \mathrm{l} / \mathrm{s}$ and $7 \mathrm{~m}$ reservoir head), head at the valve to the left and at location 8 to the right. Dotted lines correspond to water hammer without column separation. 
The main conclusion that can be drawn from the simulations is that viscoelastic pipes strongly diminish the dangers of column separation. First, cavity opening and collapse occur only one or two times instead of tens of times (as in elastic pipes). Second, pressure rises larger than Joukowsky do not occur. An additional advantage when using DVCM to model cavitation is that spurious pressure spikes are considerably damped.

\section{Summary and conclusion}

The research performed by Covas et al. [1, 2, 3] on water hammer in viscoelastic pipes has been extended by DVCM modelling of column separation similar to work by Soares et al. [16], but with different numerical implementation. Several numerical simulations including either column separation or viscoelasticity, or both, were performed and compared against available experimental results. The focus was on the calculations where both effects were included. In that case, the effects of viscoelasticity are substantial damping and less severe cavitation. The preliminary conclusion which could be of interest to designers is that in viscoelastic pipes column separation can hardly result in pressures higher than the Joukowsky pressure. Even for fast closure of an upstream valve (Figs 4 and 5) (which is similar to fast opening of a downstream valve) the combined effects of column separation and viscoelasticity did not lead to pressures greater than Joukowsky. Another conclusion is that the simplest model of column separation, DVCM, although sensitive to the numerical implementation, provided acceptable results for cavitating flow in viscoelastic pipes.

\section{References}

[1] Covas, D., Stoianov, I., Mano, J., Ramos, H., Graham, N., Maksimovic, C. 2004 "The dynamic effect of pipe-wall viscoelasticity in hydraulic transients. Part I-Experimental analysis and creep characterization", IAHR Journal of Hydraulic Research, 42(5), 516-530.

[2] Covas, D., Stoianov, I., Mano, J., Ramos, H., Graham, N., Maksimovic, C. 2005 "The dynamic effect of pipe-wall viscoelasticity in hydraulic transients. Part II-Model development, calibration and verification", IAHR Journal of Hydraulic Research, 43(1), 56-70.

[3] Covas, D., Stoianov, I., Ramos, H., Graham, N., Maksimovic, C., Butler, D. 2004 "Water hammer in pressurized polyethylene pipes: conceptual model and experimental analysis", Urban Water Journal, 1(2), 177-197.

[4] Soares, A.K., Covas, D.I.C., Reis, L.F.R. 2008 "Analysis of PVC pipe-wall viscoelasticity during water hammer", ASCE Journal of Hydraulic Engineering, 134(9), 1389-1394.

[5] Bergant, A., Simpson, A.R., Tijsseling, A.S. 2006 "Water hammer with column separation: A historical review", Journal of Fluids and Structures, 22 (2), 135-171.

[6] Bergant, A., Simpson, A.R. 1999 "Pipeline column separation flow regimes", ASCE Journal of Hydraulic Engineering, 125(8), $835-848$.

[7] Brinson, H.F., Brinson, L.C. 2008 "Polymer engineering science and viscoelasticity, an introduction”, Springer.

[8] Wineman, A.S., Rajagopal, K.R. 2000 "Mechanical response of polymers: an introduction", Cambridge University Press.

[9] Bergant A., Tijsseling, A., Vítkovský, J.P., Covas, D., Simpson, A., Lambert, M. 2008 "Parameters affecting water-hammer wave attenuation, shape and timing. Part 1: mathematical tools", IAHR Journal of Hydraulic Research, 46(3), 373-381.

[10] Bergant A., Tijsseling, A., Vítkovský, J.P., Covas, D., Simpson, A., Lambert, M. 2008 "Parameters affecting water-hammer wave attenuation, shape and timing. Part 2: case studies", IAHR Journal of Hydraulic Research, 46(3), 382-391.

[11] Bergant A., Tijsseling A.S., Vítkovský J.P., Simpson A.R., Lambert M.F. 2007 "Discrete vapour cavity model with improved timing of opening and collapse of cavities", Proceedings of the 2nd IAHR Int. Meeting of the Workgroup on Cavitation and Dynamic Problems in Hydraulic Machinery and Systems, Timişoara, Romania, Scientific Bulletin of the "Politehnica" University of Timişoara, Transactions on Mechanics, Vol. 52(66), No. 6, 117-128.

[12] Güney, M.Ş. 1977 "Contribution à l'étude du phénomène de coup de bélier en conduite viscoélastique" ("Contribution to the study of waterhammer in viscoelastic conduits"), Ph.D. Thesis, No. 274, University of Lyon, France (in French).

[13] Mitosek, M. 1997. "Study of cavitation due to water hammer in plastic pipes", Plastics, Rubber and Composites Processing and Applications, 26(7), 324-329.

[14] Greenshields, C.J., Leevers, P.S., 2000 "Failure of plastic water pipes by surge and cavitation", Proceedings of the 8th International Conference on Pressure Surges, BHR Group, The Hague, The Netherlands, 377-391.

[15] Hadj-Taïeb, L., Hadj-Taïeb, E. 2009 "Numerical simulation of transient flows in viscoelastic pipes with vapour cavitation", International Journal of Modelling and Simulation, 29(2), 206-213.

[16] Soares, A.K., Covas, D.I.C., Ramos, H.M., Reis, L.F.R. 2009 "Unsteady flow with cavitation in viscoelastic pipes", International Journal of Fluid Machinery and Systems, 2(4), 269-277.

[17] Simpson, A.R., Bergant, A. 1994 "Numerical comparison of pipe column-separation models", ASCE Journal of Hydraulic Engineering, 120(3), 361-377.

[18] Bughazem, M.B., Anderson, A. 2000 "Investigation of an unsteady friction model for waterhammer and column separation", Proceedings of the 8th International Conference on Pressure Surges, BHR Group, The Hague, The Netherlands, $483-498$.

[19] Zielke, W., Perko, H.D., Keller, A. 1989 "Gas release in transient pipe flow", Proceedings of the Sixth International Conference on Pressure Surges, BHRA, Cambridge, United Kingdom, 3-13. 
PREVIOUS PUBLICATIONS IN THIS SERIES:

\begin{tabular}{|c|c|c|c|}
\hline Number & Author(s) & Title & Month \\
\hline $10-35$ & $\begin{array}{l}\text { M.E. Hochstenbach } \\
\text { L. Reichel }\end{array}$ & $\begin{array}{l}\text { An iterative method for } \\
\text { Tikhonov regularization } \\
\text { with a general linear } \\
\text { regularization operator }\end{array}$ & June '10 \\
\hline $10-36$ & $\begin{array}{l}\text { M. Pisarenco } \\
\text { J.M.L. Maubach } \\
\text { I. Setija } \\
\text { R.M.M. Mattheij }\end{array}$ & $\begin{array}{l}\text { The aperiodic Fourier } \\
\text { modal method in contrast- } \\
\text { field formulation for } \\
\text { simulation of scattering } \\
\text { from finite structures }\end{array}$ & June '10 \\
\hline $10-37$ & $\begin{array}{l}\text { A. Bergant } \\
\text { J.M.C. van ‘t Westende } \\
\text { T. Koppel } \\
\text { J. Gale } \\
\text { Q. Hou } \\
\text { Z. Pandula } \\
\text { A.S. Tijsseling }\end{array}$ & $\begin{array}{l}\text { Water hammer and } \\
\text { column separation due to } \\
\text { accidental simultaneous } \\
\text { closure of control valves in } \\
\text { a large scale two-phase } \\
\text { flow experimental test rig }\end{array}$ & July '10 \\
\hline $10-38$ & $\begin{array}{l}\text { A.S. Tijsseling } \\
\text { Q. Hou } \\
\text { B. Svingen } \\
\text { A. Bergant }\end{array}$ & $\begin{array}{l}\text { Acoustic resonance in a } \\
\text { reservoir-pipeline-orifice } \\
\text { system }\end{array}$ & July '10 \\
\hline $10-39$ & $\begin{array}{l}\text { A. Keramat } \\
\text { A.S. Tijsseling } \\
\text { A. Ahmadi }\end{array}$ & $\begin{array}{l}\text { Investigation of transient } \\
\text { cavitating flow in } \\
\text { viscoelastic pipes }\end{array}$ & July '10 \\
\hline
\end{tabular}

